\title{
Noninvasive ventilation masks with viral filters to protect health care workers from SARS-CoV-2 / Coronavirus infections
}

Dominic Dellweg ( $\nabla$ ddellweg@freenet.de)

Fachkrankenhaus Kloster Grafschaft https://orcid.org/0000-0003-0581-3441

Peter Haidl

Fachkrankenhaus Kloster Grafschaft GmbH

Jens Kerl

Fachkrankenhaus Kloster Grafschaft GmbH

Dieter Koehler

Fachkrankenhaus Kloster Grafschaft GmbH

\section{Research}

Keywords: Sars-CoV-2, virus, surgical mask, respirator, infection, pandemic

Posted Date: April 8th, 2020

DOI: https://doi.org/10.21203/rs.3.rs-21269/v1

License: (a) (i) This work is licensed under a Creative Commons Attribution 4.0 International License. Read Full License 


\section{Abstract}

Background:There is a shortage of masks and respirators for the protection of health care professionals during the current SARS-CoV-2 / Coronavirus pandemic. Masks for non-invasive ventilation (NIV) in combination with viral-proof filters could serve as an alternative protection measure. We wanted to determine the aerosol filtering efficacies of such devices in comparison to conventional surgical masks, N95 and FFP3 respirators.

Method:Masks and respirators were mounted on a ventilated mannequin head in a test-chamber. Absorption of radioactive particles was measured compared to a non-filtered reference port.

Results: Filter efficacies were $93.3 \pm 1.5 \%$ for a ResMed AcuCare NIV-mask plus filter, $71.2 \pm 0.2 \%$ for a ResMed Mirage Quattro FX NIV-mask plus filter, $89.4 \pm 0.9 \%$ for a Loewenstein JOYCEclinc FF NIV-mask plus filter, $48.4 \pm 4 \%$ for a surgical mask with rubber band, $60.5 \pm 9.1 \%$ for a surgical mask with ribbons, $56.9 \pm 7.5 \%$ for a FFP3 respirator, $64.5 \% \pm 5.1$ for a N95 respirator. The ResMed AcuCare and the Loewenstein JOYCEclinic FF mask were more effective than any other of the tested devices $(p<0.001$ and $p=0.001$ respectively)

Conclusion:NIV masks with viral-proof filters effectively filter respirable particles. Two tested NIV masks were more effective than the tested FFP3 and N95 respirators.

\section{Introduction}

During the current pandemic with the SARS-CoV-2 virus we have to protect our health care professionals from infections with the virus. The FDA recommends the use of N95 masks in health care settings since they are designed to achieve a very close facial fit and an effective filtration of airborne particles[1]. In Europe FFP2 or FFP3 masks are recommended to protect healthcare workers from SARS-CoV-2 transmission[2]. Uncertainty in wide sections of the population resulted in panic-buying of facial masks. On February $14^{\text {th }}$ UK dentists had to stop working due to face mask shortages[3], the surgeon general of the united states, Jerome M. Adams urged the population in a tweet on February $29^{\text {th }} 2020$ to stop buying masks since this will take away resources from health care professionals[4]. Emanuel Macron, president of France, seized the nationwide supply of facial masks on March $3^{\text {rd }} 2020$ [5] and the german minister of health, Jens Spahn, banned the export of facial masks from Germany one day later [6]. Iran has temporarily freed 54.000 prisoners in hopes of minimizing contagion in Iran's penitentiaries and Iran's top prosecutor has warned, that anyone hoarding face masks and other public health equipment will risk the death penalty [7].

The classification and nomenclature of face masks is complex and regulations are different between countries. Surgical masks are loose fitting, disposable devices, that create a physical barrier between the nose and the mouth of the wearer and potential contaminants in the immediate environment [1]. They were initially designed to prevent the contamination of surgical sites by the operating staff and their effectiveness is measured by the prevention of bacterial contamination caused by the wearer $[8,9]$. 
N95 respirators (USA) and facial filtering pieces (FFP devices, Europe) are designed to protect both, the patient and health care personnel from the spread of microorganisms, body fluids, and particulate material $[1,10]$. N95 respirators are class II devices regulated by the FDA, under 21 CFR 878.4040, and CDC NIOSH under 42 CFR Part 84 [1]. FFP respirators are regulated according to the European norm EN 149 [10]. The FDA norm requires tests by means of an sodium chloride aerosol with a particle size distribution with count median diameter of $0.075 \pm 0.020 \mu \mathrm{m}$ [11]. The norm requires an absorption rate of $95 \%$. FFP respirators are grouped in three classes FFP 1, FFP 2 and FFP 3 . They are required to absorb $80 \%, 94 \%$ and $99 \%$ of a sodium chloride aerosol respectively.

The shortage of disposable face masks as lined out previously raises the question, if multi-use facial protection devices could be a solution to the problem. Such a system could be built by the combination of non-vented masks which are used for non-invasive ventilation in combination with a viral/bacterial-proof filter as lined out in figure 1.

We wanted to compare the filtration efficacy of such reusable devices as shown in figure 1 in comparison to disposable N95 and FFP3 respirators as well as surgical masks in an experimental setting including the simulation of spontaneous breathing.

\section{Materials And Method}

\section{Experimental setup:}

We prepared a mannequin head from a commercially available dummy head (Respironics, Murrysville, PA, USA, Figure 2).

Nasal and mouth openings of the mannequin connect to a tube that exits the head on the backside. The sensitive areas of the face were covered with a soft wound dressing (Allevyn plus Adhesive, Smith+Nephew, London, UK) in order to simulate the elastic properties of human skin.

Experiments were conducted inside an airtight transparent plastic box of 70 liters volume (Iris 70 liter, model \# 135455, IRIS Ohyama, Sendai, Japan, figure 3).

We installed in total four $22 \mathrm{~mm}$ tube connectors/outlets as shown on figure 3 which were sealed with a two-component bonding agent. The connector on the front side (front1) of the box was connected to a nebulizer (Pari LC Sprint Star, Pari, Starnberg, Germany), the exhalation port of the nebulizer was sealed with a filter (Iso-Gard \#19212, Teleflex Medical GmbH, Fellbach, Germany) in order to prevent contamination. The three connectors on the backside of the box were utilized as follows: 
The first outlet (back1) was connected to the backside of the dummy head inside the box by means of a piece of standard single use ventilator tubing (1574000, Intersurgical, Sankt Augustin, Germany). The second outlet on the backside (back2) was connected to a tube that extended freely into the box and ended abreast to the frontside of the dummy head. The third outlet on the backside (back3) was inserted for free air circulation during simulated ventilation. Back1, back2 and back3 outlets were equipped with a filter in order to collect the radioactive particles. Outlets back1 and back2 were then connected to separate chambers of an artificial lung (dual adult test lung model 5600i, Michigan Instruments, Kentwood, MI, USA figure 3). The two chambers of the artificial lung were interlocked for simultaneous use.

\section{Aerosol and aerosol application:}

We nebulized isotonic saline containing $150 \mathrm{MBq}{ }^{99 \mathrm{~m}}$ TC-DTPA (99mTc-diethylenetriamine pentaacetate (DTPA)) per ml by means of a Pari LC Sprint Star nebulizer (Pari, Starnberg, Germany, figure 3). The nebulizer was filled with $6 \mathrm{ml}$ solution. The nebulizer output Rate equals $360-500 \mathrm{mg} / \mathrm{min}$. The aerosol had a mass median aerodynamic diameter (MMAD) of $2.4-3.3 \mu \mathrm{m}$. For every test run the nebulizer delivered the aerosol continuously for 25 seconds.

\section{Simulation of breathing:}

Breathing was simulated 10 seconds after nebulization was stopped by manual movement of the two blocked chambers of the breathing simulator for ten times within 50 seconds, generating a volume of one liter per lung-chamber. The volume was visually controlled by means of the build in volume scale of the Michigan lung. The respiratory rate was controlled by means of a metronome (EumLab for Iphone, Xanin Technology GmbH, Berlin).

\section{Measurement sites and measurement of radioactivity:}

Filter back2 served as a reference for unfiltered breathing, filter back1 collected radioactive particles that passed through the dummy head. A test run without filtering devices on the dummy face revealed equal aerosol deposition on outlets back1 and back2. We confirmed complete absorption of the aerosol by a single filter by placing a second filter behind the first one which showed no radioactivity after a test run. Filters were then positioned under a Gamma camera (ECAM Scintron, Medical imaging electronics GmbH, Seth, Germany) and radioactivity was counted for one minute. Regions of interest (ROI's) were placed around the spots of back1 and back2 filters (figure 4). A third ROI apart from the filter spots measured background activity. Activity was measured in total counts per minute.

\section{Test runs:}


Tested filtering devices are shown in figure 5 and 6:

The devices were mounted onto the dummy face as recommended by the manufacturer. Mouldable nasal straps of surgical, FFP3 and N95 masks were adjusted to optimal fit the nose bridge. Noninvasive ventilation masks were attached with the harness, the ventilation port was connected to a filter as shown in figure 1. Every setting was tested three times. For every test run a new device was mounted.

We also measured the efficacy of a surgical mask cloth that was stretched and fixed over a funnel as well as the filtering efficacy of a woven scarf wrapped around the dummy head.

\section{Analysis and statistics}

In every test run the filter activity of back1 represents the amount of unfiltered particles.

Activity in filter back2 serves as the unfiltered reference. Background activity was subtracted from back1 and back2 filter counts. The ratio back1 and back2 represents the efficacy of the applied filtering device in \%. One hundred minus efficacy represents the ratio that passed the tested filtering device. For multiple comparison we used ANOVA. The LSD test was used for post hoc analysis. A $p<=0,05$ was considered significant. SPSS version 26 was used for statistical analysis.

\section{Results}

Filter efficacy was $93.3 \pm 1.5 \%$ for the ResMed AcuCare NIV-mask, $71.2 \pm 0.2 \%$ for the ResMed Mirage Quattro FX NIV-mask, $89.4 \pm 0.9 \%$ for the Loewenstein JOYCEclinc FF NIV-mask, $48.4 \pm 4 \%$ for the surgical mask with rubber band, $60.5 \pm 9.1 \%$ for the surgical mask with ribbons, $56.9 \pm 7.5 \%$ for the FFP3 respirator, $64.5 \% \pm 5.1$ for the N95 respirator, $87.2 \pm 0.7 \%$ for the surgical mask cloth and $42.1 \pm$ $7.3 \%$ for the woven scarf. Figure 7 displays measurements, table 1 shows $p$-values and confidence intervals.

(see Table 1 in the Supplementary Files)

\section{Discussion}

The major finding of our investigation is that two of three reusable NIV masks in combination with a viralproof filter as shown in figure 1 and 6 had a higher filtration efficacy than surgical masks, N95 and FFP3 respirators. The second and more important finding is that N95 and FFP 3 respirators did not reach the required filtration rate of $95 \%$ (N95 respirator) and $99 \%$ (FFP3 respirator) in our experimental setting. Regulation 42 CFR Part 84 and ISO EN 149 norm describe the filter efficacy level determination for N95 and FFP3 respirators respectively. The respective norms use different procedural standards. 42 CFR Part 
84 specifies to use a constant flow of a sodium chloride aerosol over the test filter which is mounted on a test fixture. The aerosol concentration is then measured behind the filter. Simulation of active breathing which might provoke leakage is not required. ISO EN 149 requires to test filters on an experimental subject while a constant flow of sodium chloride aerosol at a certain flow and pressure is nebulized inside a chamber. A sampling line is passed through a hole in the filter and sodium concentration is measured directly behind the filter medium while the subject is running on a treadmill at six kilometers an hour. Such a sampling line in central position could be in danger of missing lateral leakage-flows.

Overall one can determine three types of leakages. First, the amount of aerosol penetrating the filter itself, second the aerosol passing in between filter and skin and third a so-called slack-leakage that passes the expiration valve during early inspiration if an expiration valve is built in. Images from the gamma camera suggest that the main leak flow occurs around the nasal edge of the respirators (figure 8 ).

The increased leakage of the measured FFP3 device as compared to the N95 filter (figure 7, table 1) could be due to the fact, that the FFP3 device was equipped with an expiratory valve causing a slack-leakage. In our experiment our particle sampling filters were positioned at a more distal site (back 1 , see figure 3 ) compared to 42 CFR Part 84 and ISO EN 149 specifications. This ascertains, that neither form of leakageflow is missed during the experiment.

The airflow bypassing the filter decreases filtration efficacy. We found that more than one third of the particle load bypassed N95 and FFP3 respirators as well as surgical masks. Infection with pathogens such as viruses depend on many factors. The major factors are particle load in the inspired air, exposure time and minute ventilation during exposure. It is also of importance whether the pathogen targets the upper or lower respiratory tract. Furthermore, the respiratory pattern determines impaction, diffusion and sedimentation of inhaled particles. If the lower than expected filtration efficacy of the tested devices translates into an increased infection risk, is beyond the scope of our investigation. The large difference between norm specification and our measurements however is worrisome. Previous bench studies have observed a significant inward leakage of $\mathrm{N} 95$ respirators especially with increasing inspiratory effort and breathing frequency [12-14]. Previous clinical studies have found significant infection rates despite the use of appropriate respirator systems [15-18]. Two large field studies and one metanalysis even found, that surgical masks were non-inferior to N95 respirators as measured by infection rates $[15,18,19]$.

The results of our investigation raise the question, if N95 and FFP3 respirators are appropriate to protect health care workers during contact with infected patients especially in the face of the current SARS-CoV-2 pandemic.

Despite the fact, that the tested masks for non-invasive ventilation were not designed for the purpose of infection control, they outperformed the N95 and FFP3 respirators as well as the surgical masks. It is of particular importance, that the variability of test results is smaller for the tested NIV masks compared to respirators and surgical masks (figure 7). For every test run the tested filter medium was mounted by the 
same researcher (DD) who aimed to achieve optimal fit of the device. Therefore, the wider distribution of measured values indicates, that the danger of achieving suboptimal fit appears to be higher for respirators and surgical masks. If surgical masks are fitted properly to the face, they achieve similar results as respirators which can be explained by the good filtration ratio of the mask cloth as seen in figure 7. Using a scarf for protection as frequently seen on public media is probably not sufficient to protect from viral transmission and cannot be recommended.

NIV mask are designed to achieve optimal air-tightness during positive pressure ventilation. For this purpose, some of the devices are designed in a way, that positive pressure pushes an additional rubber lip towards the skin of the user. Among the tested devices the ResMed Mirage Quattro FX mask (figure 6) has such a rubber lip over the bridge of the nose. When generating negative pressures during inspiration, there was a recognizable leakage in this area. The fact that NIV-ventilation masks could be cleaned with antimicrobial agents for multiple use offers a solution for the current shortage of single use respirators and masks. Furthermore, NIV masks are available in different sizes. The viral-proof filters, that we attached to the ventilation masks have a manufacturer guaranteed lifetime of 24 hours during continuous mechanical ventilation and could potentially be used for several days if used intermittently. When we equipped our healthcare professionals with the combination of non-vented NIV masks with a viral filter as shown in figure 1, some members of our staff reported difficulties of breathing. We were able to resolve this problem by adding a T-piece and a second filter to the system as shown in figure 6-F.

\section{Conclusion}

In our experiments N95 and FFP3 respirators were less effective than required by official regulations when tested during simulation of spontaneous breathing in our bench model.

Non-vented noninvasive ventilation mask in conjunction with viral filters could serve as a more effective alternative. These systems are reusable and could solve the current supply problem for single use respirators and masks.

\section{Limitations:}

Our static bench model does not take head and/or body movements into account, which appears to be a relevant practical problem [13]. For this reason, our model could underestimate the leakage. We ventilated our model with room air which has less humidity than human air in natural airways. Any impact of humidity can therefore not be investigated with our model. We tested only a small proportion of available mask and respirator systems. More research is needed to investigate, if our findings pertain for other devices.

\section{Declarations}

\section{Ethics approval and consent to participate:}


Not applicable

\section{Consent for publication:}

All authors have read the manuscript and agree to the publication in Respiratory Research.

\section{Availability of data and materials:}

Data available on request from the authors.

\section{Competing interest:}

None of the authors has a competing interest in the matter of subject.

\section{Funding:}

We received no external funding

\section{Authors' contributions:}

DD had the idea to use the combination of NIV masks in combination with viral filters to protect health care workers from transmission of infective particles. DD, PH, JK and DK designed the experimental setup and conducted measurements. DD and DK analyzed the data. DD drafted the paper. All authors have read the document and agree with the content.

\section{Acknowledgements}

Not applicable

\section{Author information:}

Dominic Dellweg, Ph.D.

Kloster Grafschaft

Annostr. 1

57392 Schmallenberg

Germany

Mail: d.dellweg@fkkg.de

\section{References}


1. N95 Respirators and Surgical Masks (Face Masks) [https://www.fda.gov/medical-devices/personalprotective-equipment-infection-control/n95-respirators-and-surgical-masks-face-masks]

2. Empfehlungen des Robert Koch-Institutes zu Hygienemaßnahmen im Rahmen der Behandlung von Patienten mit einer Infektion durch SARS-CoV-2 [https://www.rki.de/DE/Content/InfAZ/N/Neuartiges_Coronavirus/Hygiene.html]

3. FACE MASK SHORTAGES AMID CORONAVIRUS OUTBREAK MEAN DENTISTS IN U.K. MAY NEED TO STOP WORKING [https://www.newsweek.com/face-mask-shortages-amid-coronavirus-outbreakmean-dentists-uk-may-need-stop-working-1487305]

4. Surgeon General Urges the Public to Stop Buying Face Masks [https://www.nytimes.com/2020/02/29/health/coronavirus-n95-face-masks.html]

5. France fights mask hoarding; Virus deaths soar in Italy [https://abcnews.go.com/Health/wireStory/schools-close-french-german-virus-cluster-zones69356319]

6. Bundesgesundheitsminister Jens Spahn gibt eine Regierungserklärung zur Bekämpfung des Coronavirus ab [https://www.bundesgesundheitsministerium.de/presse/reden/regierungserklaerungcoronavirus.html]

7. Iran's Coronavirus Response: Pride, Paranoia, Secrecy, Chaos [https://www.nytimes.com/2020/03/03/world/middleeast/coronavirus-iran.html]

8. Frappier A, Forte L: A Bacteriological Study of the New Surgical Mask "Jel". Can Med Assoc J 1936, 34(5):547-549.

9. Gauthier PP: A Comparative Study of Three Surgical Masks. Can Med Assoc J 1937, 37(3):250-252.

10. Atemschutzmaske [https://de.wikipedia.org/wiki/Atemschutzmaske]

11. 42 CFR $\S 84.181$ - Non-powered air-purifying particulate filter efficiency level determination [https://www.law.cornell.edu/cfr/text/42/84.181]

12. He X, Reponen T, McKay R, Grinshpun SA: How does breathing frequency affect the performance of an $\mathrm{N} 95$ filtering facepiece respirator and a surgical mask against surrogates of viral particles? $\mathrm{J}$ Occup Environ Hyg 2014, 11(3):178-185.

13. Grinshpun SA, Haruta H, Eninger RM, Reponen T, McKay RT, Lee SA: Performance of an N95 filtering facepiece particulate respirator and a surgical mask during human breathing: two pathways for particle penetration. J Occup Environ Hyg 2009, 6(10):593-603.

14. Rengasamy S, Eimer BC, Szalajda J: A quantitative assessment of the total inward leakage of $\mathrm{NaCl}$ aerosol representing submicron-size bioaerosol through N95 filtering facepiece respirators and surgical masks. J Occup Environ Hyg 2014, 11(6):388-396.

15. Loeb M, Dafoe N, Mahony J, John M, Sarabia A, Glavin V, Webby R, Smieja M, Earn DJ, Chong S et al: Surgical mask vs $\mathrm{N} 95$ respirator for preventing influenza among health care workers: a randomized trial. JAMA 2009, 302(17):1865-1871. 
16. Maclntyre CR, Wang Q, Cauchemez S, Seale H, Dwyer DE, Yang P, Shi W, Gao Z, Pang X, Zhang Y et al: A cluster randomized clinical trial comparing fit-tested and non-fit-tested N95 respirators to medical masks to prevent respiratory virus infection in health care workers. Influenza Other Respir Viruses 2011, 5(3):170-179.

17. Maclntyre CR, Wang Q, Seale H, Yang P, Shi W, Gao Z, Rahman B, Zhang Y, Wang X, Newall AT et al: A randomized clinical trial of three options for $\mathrm{N} 95$ respirators and medical masks in health workers. Am J Respir Crit Care Med 2013, 187(9):960-966.

18. Radonovich LJ, Jr., Simberkoff MS, Bessesen MT, Brown AC, Cummings DAT, Gaydos CA, Los JG, Krosche AE, Gibert CL, Gorse GJ et al: N95 Respirators vs Medical Masks for Preventing Influenza Among Health Care Personnel: A Randomized Clinical Trial. JAMA 2019, 322(9):824-833.

19. Smith JD, MacDougall CC, Johnstone J, Copes RA, Schwartz B, Garber GE: Effectiveness of N95 respirators versus surgical masks in protecting health care workers from acute respiratory infection: a systematic review and meta-analysis. CMAJ 2016, 188(8):567-574.

\section{Table 1}

Due to technical limitations Table 1 is available as a download in the Supplementary Files.

\section{Figures}




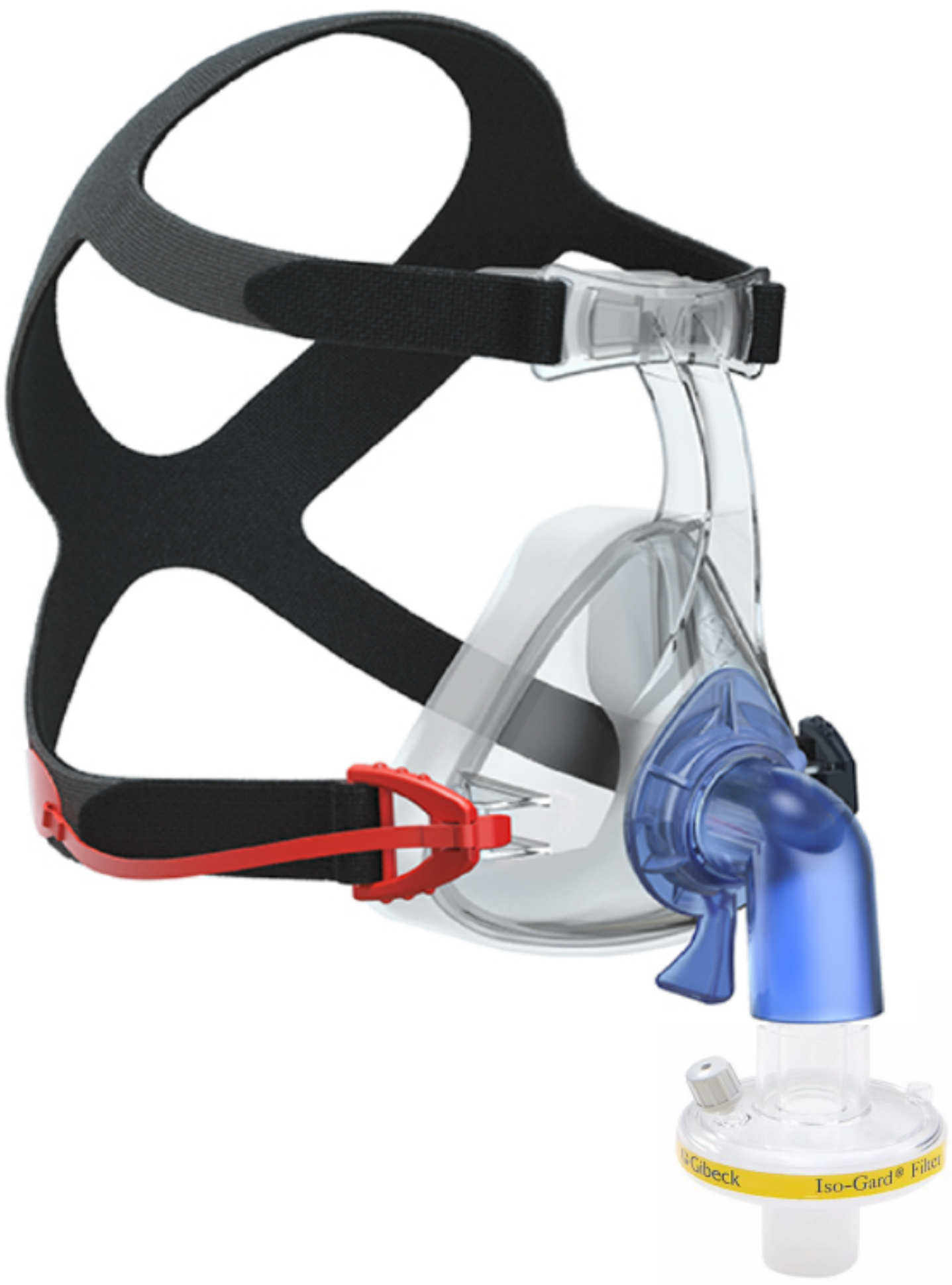

Figure 1

Non-vented NIV mask in combination with a viral-proof filter 


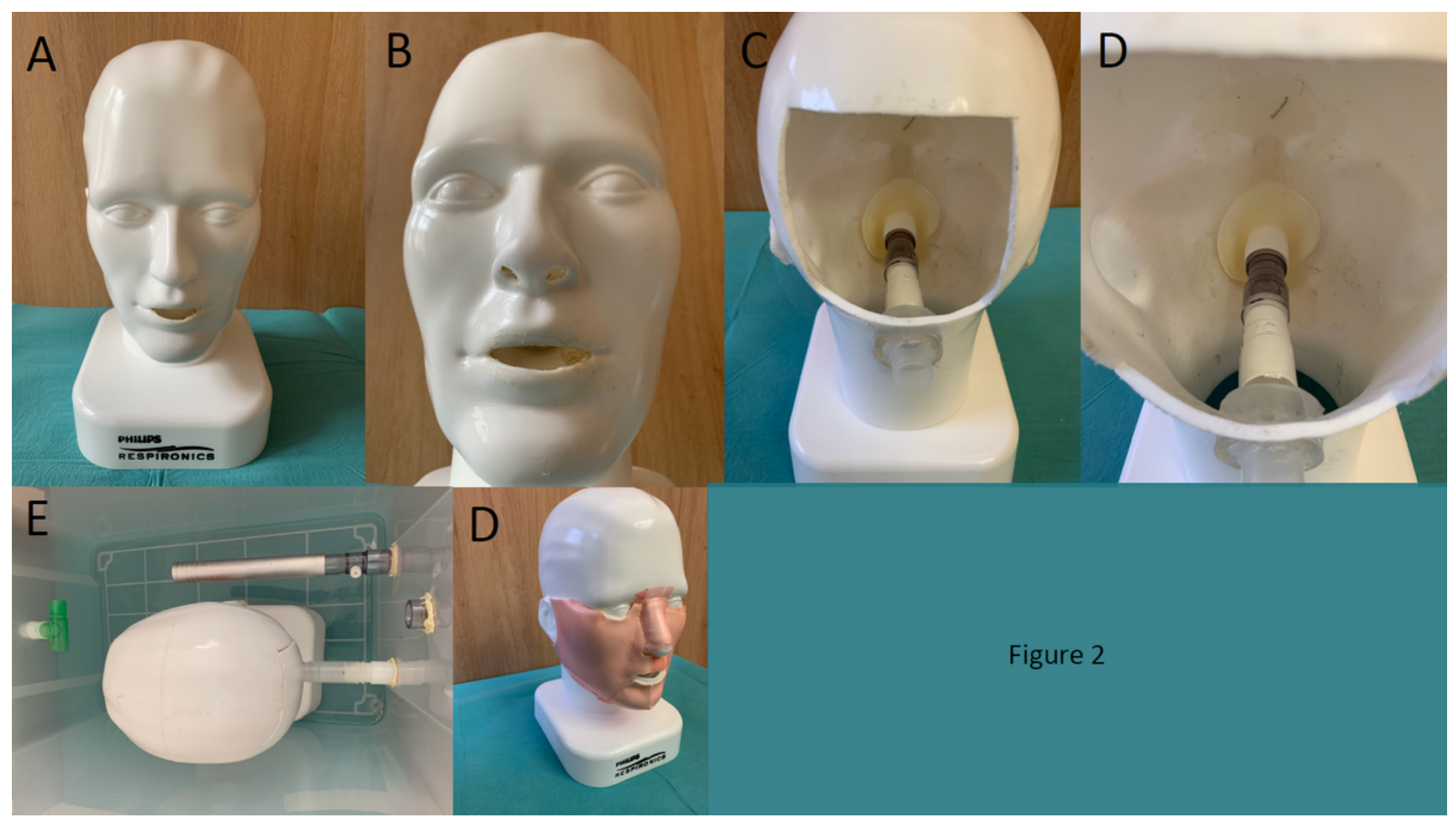

Figure 2

Mannequin head. Nasal and mouth openings of the mannequin connect to a tube/outlet that exits the head on the backside (A-D). This outlet connects to a filter outside the measuring-box (E). A soft wound dressing simulates the elastic properties of facial skin (D) 


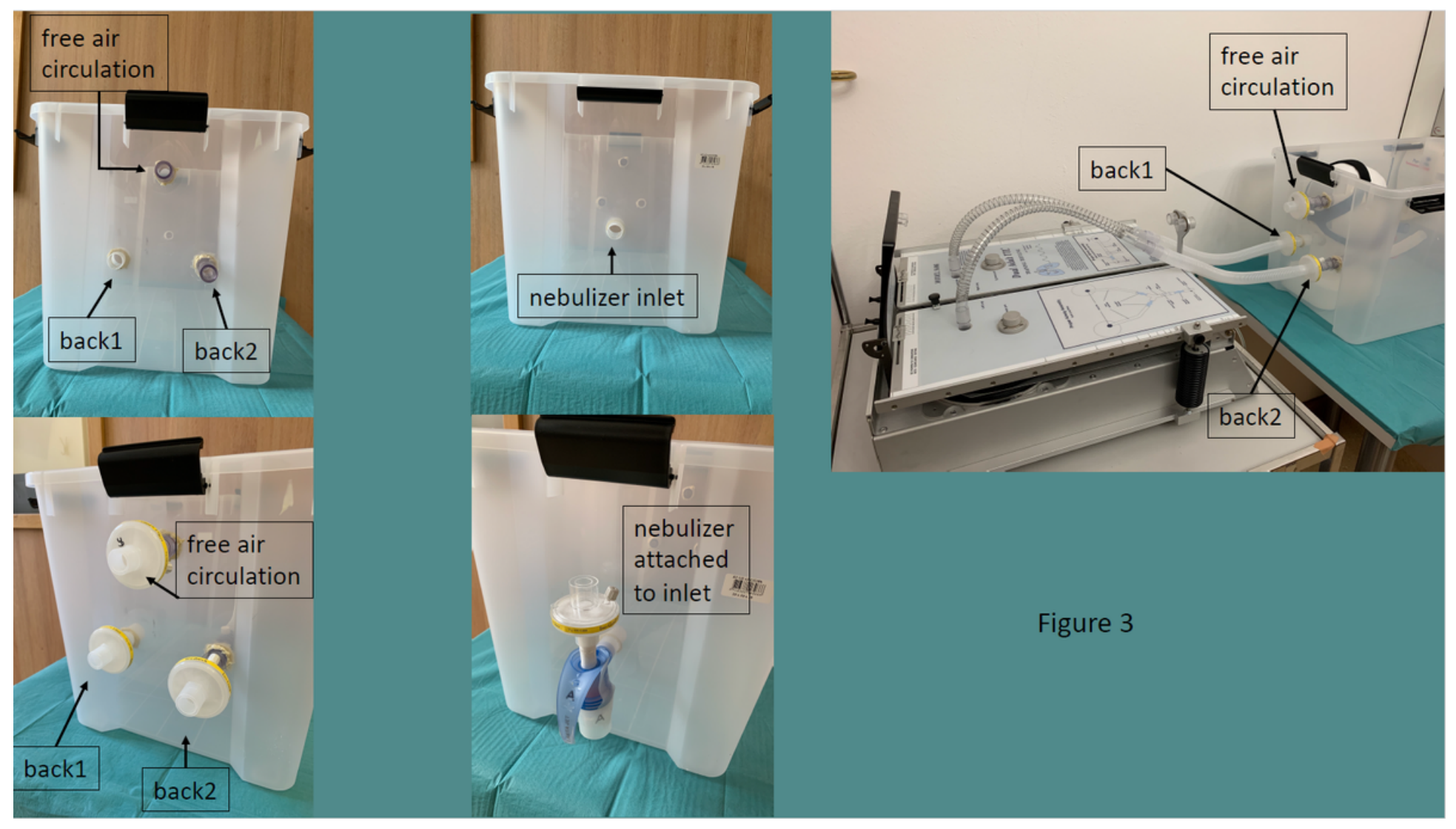

\section{Figure 3}

Airtight transparent measuring box connected to a dual test lung, see text for details

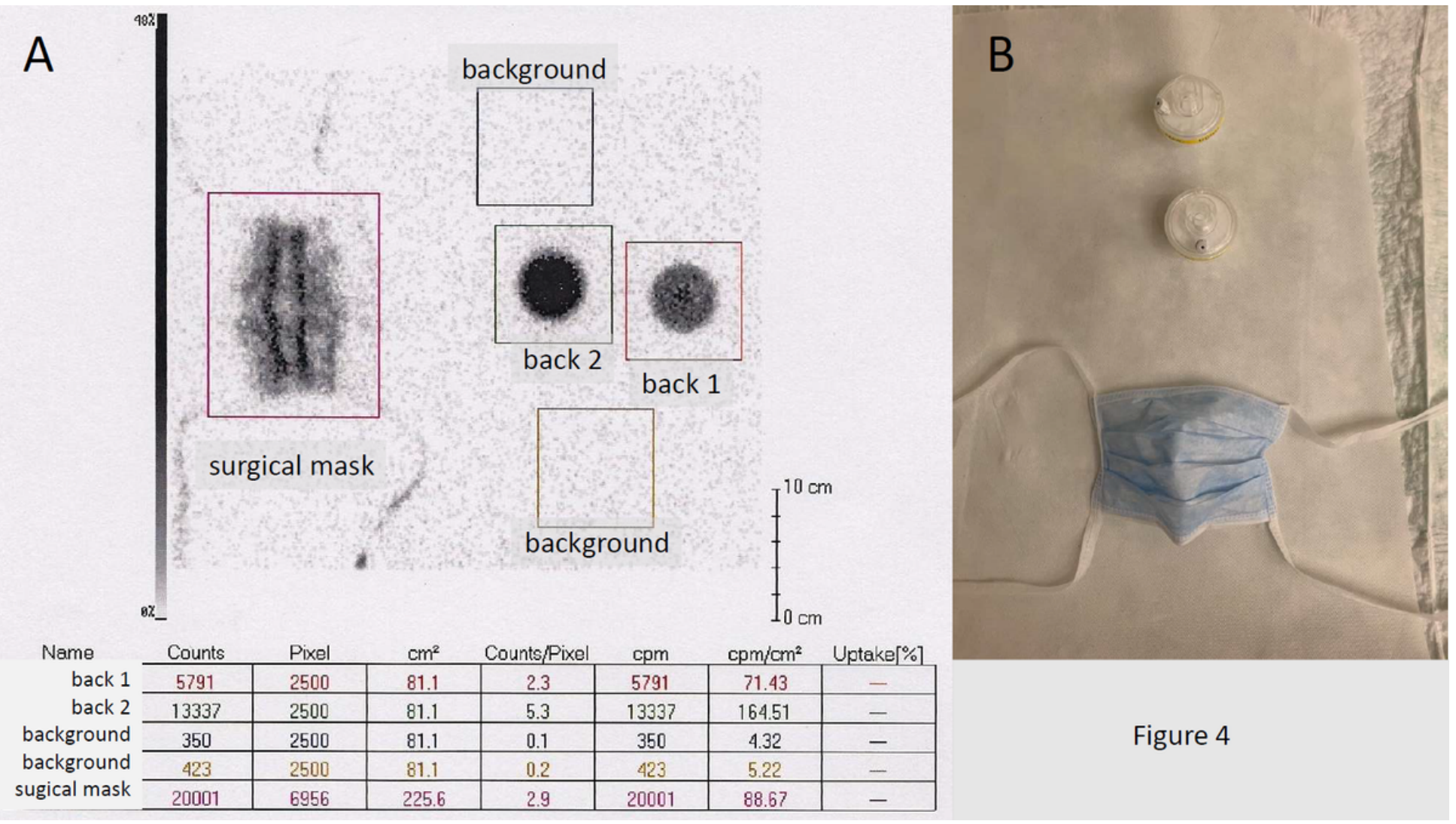

Figure 4 
Part A shows the scintigraphic image of the radioactive items shown in part $B$

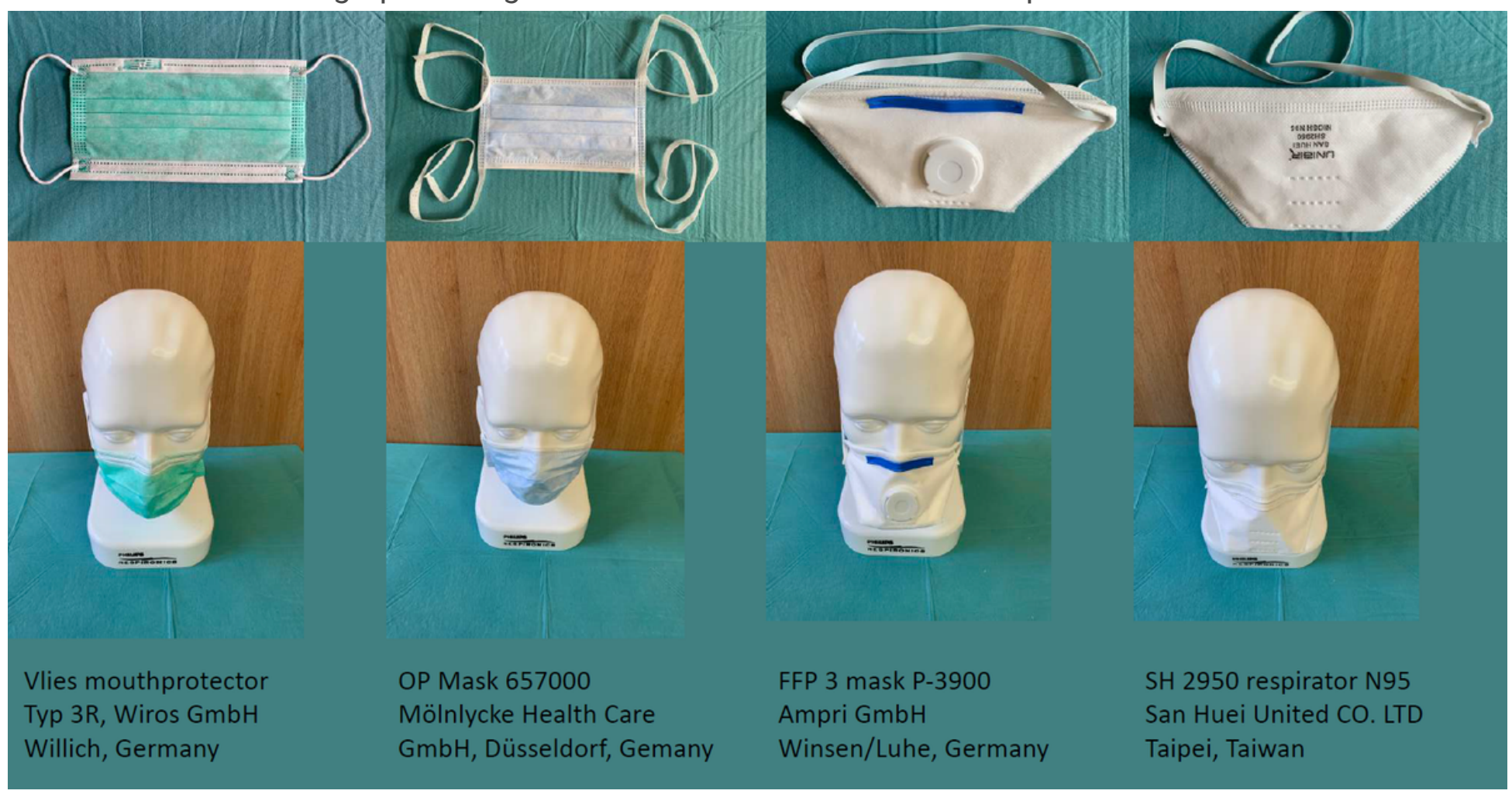

\section{Figure 5}

Tested masks and respirators

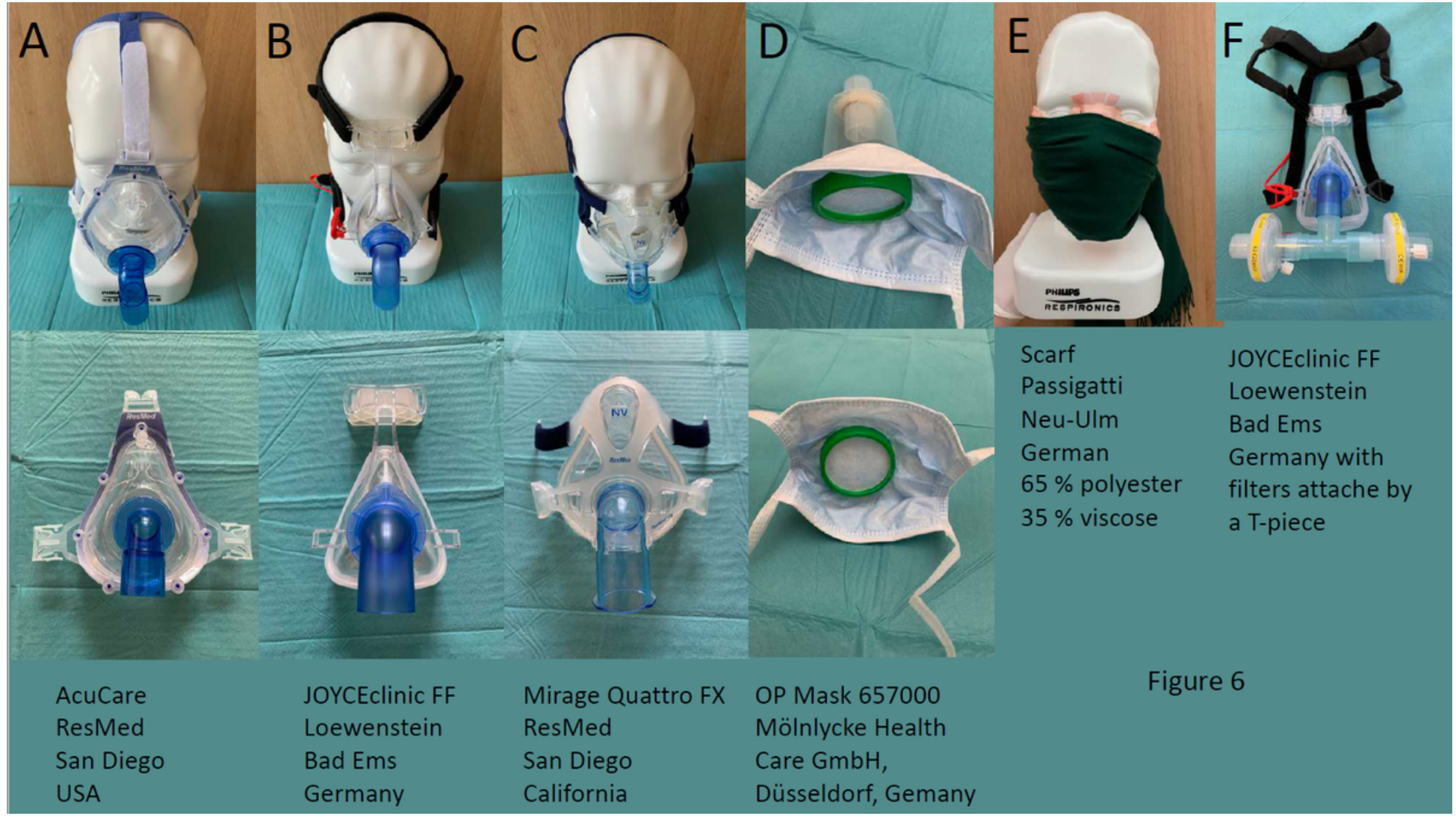

\section{Figure 6}


Tested NIV-masks (A-C), mask-cloth streched over a plastic cup (D), woven scarf (E). Attachment of two filters for the reduction of breathing resistance $(F)$

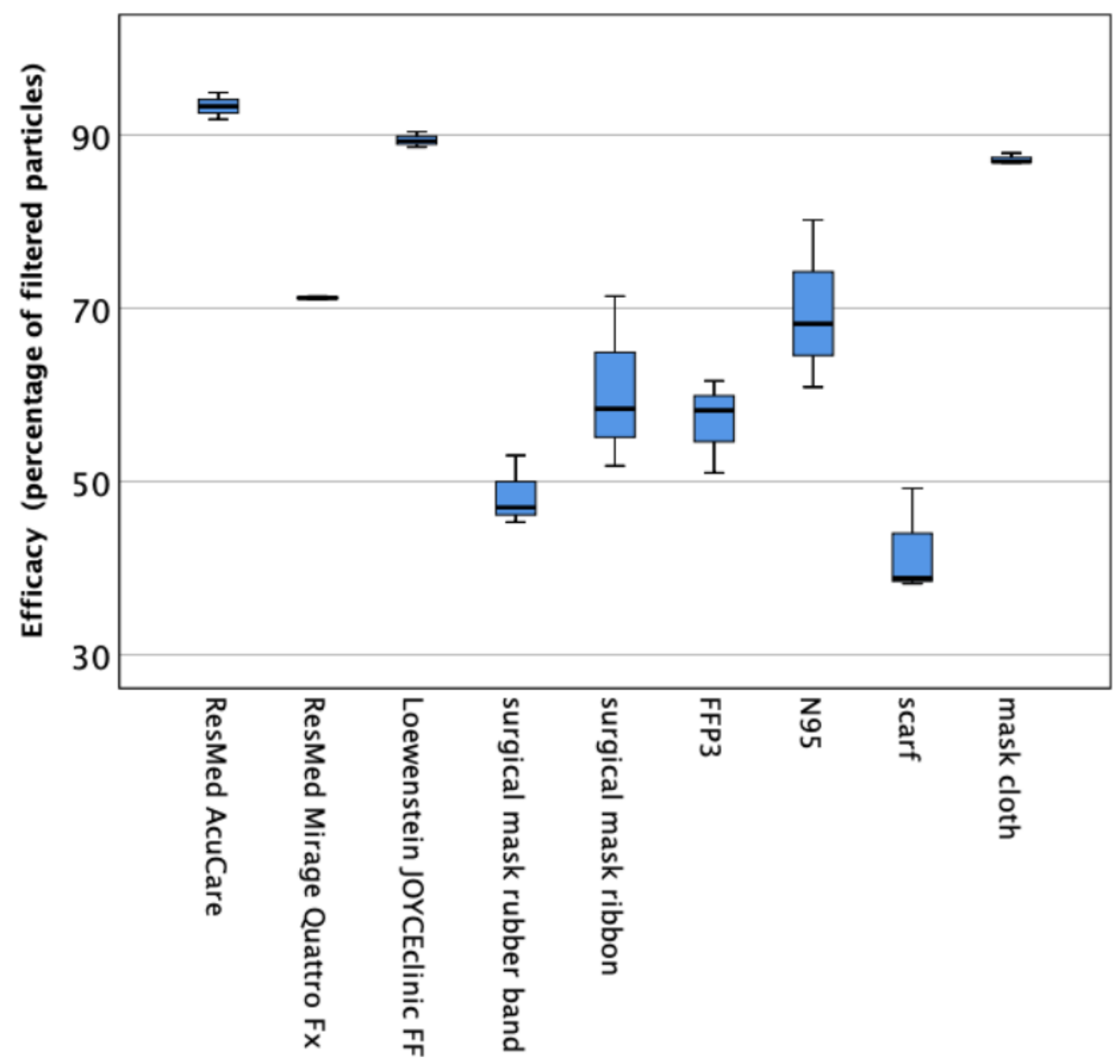

Figure 7

Filtering efficacy of the tested devices 
A
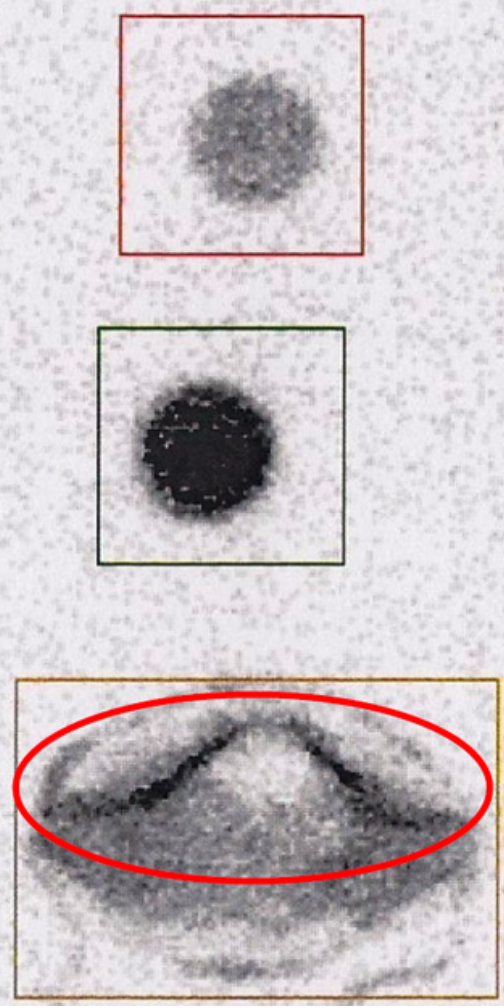
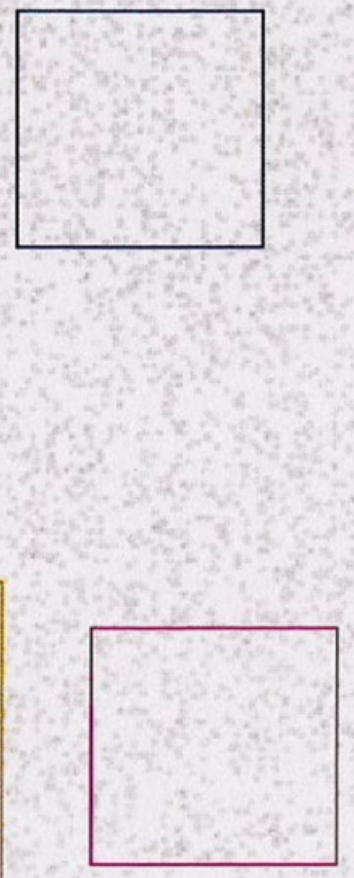

B

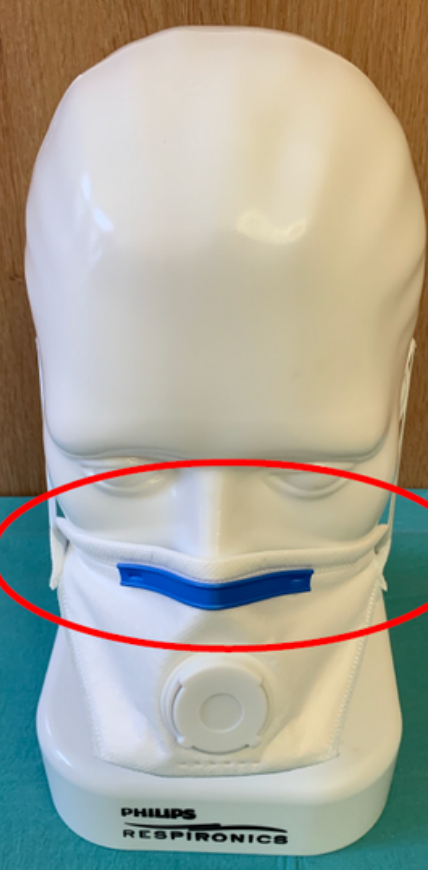

Figure 8

\section{Figure 8}

Increased radioactivity is seen around the upper edge of the respirator indicating leak-flow in this area

\section{Supplementary Files}

This is a list of supplementary files associated with this preprint. Click to download.

- Table1.pdf 